\title{
Review Article \\ Orofacial Clefts: A Worldwide Review of the Problem
}

\author{
P. Agbenorku \\ Reconstructive Plastic Surgery and Burns Unit, Department of Surgery, Komfo Anokye Teaching Hospital, \\ School of Medical Sciences, College of Health Sciences, Kwame Nkrumah University of Science and Technology, \\ Kumasi, Ghana \\ Correspondence should be addressed to P. Agbenorku; pimagben@yahoo.com
}

Received 1 April 2013; Accepted 30 April 2013

Academic Editors: K. Kusumoto, C. Shipkov, and B. G. Ulusal

Copyright (C) 2013 P. Agbenorku. This is an open access article distributed under the Creative Commons Attribution License, which permits unrestricted use, distribution, and reproduction in any medium, provided the original work is properly cited.

Orofacial cleft is one of the commonest congenital abnormalities which impacts negatively on the life of the individual and to a large extent affects the family. Caused by the interaction of environmental and genetic factors, this abnormality brings about decreased quality of life. Management of this abnormality entails a team involving a cleft surgeon, speech therapist, dentist, orthodontists, and so forth. This study involves the review of the various literatures on orofacial clefts, discussing the problems on the genetic basis, associated syndromes, and their management. Counseling of prospective mothers should be promoted to ensure that the abnormality is prevented at the early stages. Education on orofacial clefts should be promoted to create awareness on its preventive measures. Much attention must be geared towards cleft genetics studies to identify potential risk factors which might be predisposing individuals to the anomaly.

\section{Introduction}

Orofacial clefts (OFCs) are common congenital malformations of the lip, palate, or both caused by complex genetic and environmental factors [1]. OFC may involve the lip, the roof of the mouth (hard palate), or the soft tissue in the back of the mouth (soft palate). OFC also involves structures around the oral cavity which can extend onto the facial structures resulting in oral, facial, and craniofacial deformity [2]. A cleft lip/palate may impact negatively on an individual's self-esteem, social skills, and behaviour especially among girls $[3,4]$. Generally, boys are affected more than girls with a ratio of about $3: 2$ [5]. Males are more likely than females to have a cleft lip with or without cleft palate, while females are at a slightly greater risk for cleft palate alone [6, 7]. Since facial mesenchyme is derived from neural crest, it is postulated that periconceptional folic acid supplementation may reduce the occurrence of offspring with orofacial clefts [8]. Zinc also is important in fetal development, and deficiency of this nutrient causes isolated cleft palate and other malformations in animals; other nutrients such as riboflavin and vitamin A are also essential [9]. Preventive efforts might entail manipulation of maternal lifestyle, improved diet and use of multivitamin and mineral supplements, avoidance of certain drugs and medicines, and general awareness of social, occupational, and residential risk factors [2].

Genetic Basis of Orofacial Clefts. Genetic inheritance means that a child's features are "inherited" or passed from parent to child [10]. There are two types of inheritance: the singlegene inheritance where a feature appears as a result of a single gene carried by one parent and the multifactorial inheritance where a feature appears as a result of a number of genetic and nongenetic factors, such as alcohol, drugs, and environmental factors [10]. Orofacial development is a complex process that involves many genes and signaling pathways [11]. Alterations in one or more of these genes could cause one of the commonest malformations in humans: cleft lip with or without cleft palate or cleft palate alone (CL $\pm \mathrm{P}$, CP) [12].

\section{The Problem}

2.1. Epidemiology. The prevalence of OFCs varies from $1 / 500$ to $1 / 2500$ births depending on the geographic origin, racial and ethnic backgrounds, and socioeconomic status $[13,14]$. Also Das stated that Asians have the highest risk $(14: 10,000$ 
births) followed by whites (10:10,000 births) and African Americans (4:10,000 births) [15]. Cleft lip, with or without cleft palate, affects one in 700 babies annually and is the fourth most common birth defect in the United States. Clefts occur more often in children of Asian, Latino, or Native American descent [16]. Reports of birth prevalence of OFCs from different African populations vary widely, from as low as $0.3 / 1,000$ reported in Nigeria [17] to $1.65 / 1,000$ reported in Kenya [18]. In Malawi, there is a reported low prevalence rate for cleft lip and/or palate, 0.7 per 1,000 live births [19]. Suleiman et al. (2005) found that the prevalence rate of clefting among a group of Sudanese hospital newborns in the city of Khartoum is 0.9 per 1,000 live births [20]. In Ghana, a survey conducted in the Wudoaba communities revealed a CL/CP prevalence of 5.0 per 1,000 people [21].

2.2. Risk of Occurrence. The risk of recurrence of a cleft condition is determined by a number of factors that are often unique in a particular family, and these include the number of family members with clefts, how closely related these people are, the race and sex of the affected individuals, and the type of cleft each person has [22]. Once parents have a child with a cleft, the risk that the next child (each succeeding child) will be affected is $2-5 \%$ ( 2 to 5 chances in 100). If there is more than one person in the immediate family with a cleft, the risk rises to $10-12 \%$ (roughly 1 chance in 10 ). An individual who is the only one in his or her family with a cleft has $2-5 \%$ chances that his or her child will have a cleft ( 2 to 5 chances in 100). If the individual with the cleft also has a close relative with a cleft, the risk increases to $10-12 \%$ (roughly 1 in 10 ) that a child will have a cleft. Finally, the unaffected siblings of an individual with a cleft have a roughly $1 \%(1$ in 100$)$ risk of having a baby with a cleft. This may rise to 5-6\% (5 to 6 chances in 100) if more than one close family member has a cleft. If a syndrome is involved, the risk for recurrence within the family could be as high as 50\% (1 chance in 2) [22].

2.3. Causes. The aetiology of OFCs is complex, including multiple genetic and environmental factors [23]. Oral clefts frequently occur in combination with a wide range of chromosomal abnormalities and syndromes (trisomy 13, amniotic band anomalad, Fryns syndrome, Meckel syndrome, Stickler syndrome, Treacher Collins syndrome, van der Woude syndrome, Velocardiofacial syndrome, etc.) [24] and environmental factors such as medication during pregnancy, maternal alcohol consumption and smoking, dietary and vitamin deficiencies, diabetes, environmental toxins, altitude, birth order, socioeconomic status, and parental age [2529]. Other genetic factors that may affect the presence of OFCs include maternal ability to maintain red blood cell zinc concentrations and myoinositol concentrations (a hexahydroxycyclohexane sugar alcohol) [30]. Maternal ability to maintain adequate levels of vitamins B6 and B12 and fetal ability to utilize these nutrients are also seen as a factor in the development of oral clefts when these nutrients are not metabolized properly since errors in DNA synthesis and transcription may occur [31].

Drugs play a limited role in the aetiology of cleft lip or palate $(\mathrm{CL} / \mathrm{P})$; amoxicillin, phenytoin, oxprenolol, and thiethylperazine may have some association with $(\mathrm{CL} / \mathrm{P})$, while carbamazepine and oxytetracycline may have some association with posterior cleft palate (PCP) during the early stages of pregnancy [32]. In addition, mothers with the MTHFR 677TT OR MTHFR 1298CC genotype and low periconceptional folate intake were found to have an increased risk for cleft lip with or without palate among their offspring [31, 33]. Drugs which interfere with folate metabolism, such as phenytoin, are known to have teratogenic effects which include oral cleft, growth retardation, limb defects, and other craniofacial deformities. Maternal intake of vasoactive drugs which include pseudoephedrine, aspirin, ibuprofen, and amphetamine as well as cigarette smoking has been associated with higher risk of oral clefts [34-36]. Anticonvulsant medications such as phenobarbital, trimethadione, valproate, and Dilantin have also been documented to increase incidence of cleft lip/cleft palate $[37,38]$. Other drugs such as acne medications containing Accutane and methotrexate, a drug commonly used for treating cancer, arthritis, and psoriasis, may also cause cleft lip and cleft palate [16].

2.4. Diagnosis. Sometimes OFCs are diagnosed by prenatal ultrasound, but there is no systematic screening for orofacial clefts [39]. Most often, orofacial clefts are diagnosed after the baby is born. However, sometimes minor clefts (e.g., submucous cleft palate and bifid uvula) might not be diagnosed until later in life. Cleft lip can be easily diagnosed by performing ultrasonography in the second trimester of pregnancy when the position of the fetal face is located correctly [40]. Prenatal diagnosis gives parents the advantage of having time to prepare emotionally for the birth and become knowledgeable about the birth defect.

2.4.1. Ultrasound Diagnosis. New techniques for prenatal diagnosis have been reported by some authors. Campbell et al. reported a novel technique involving a reverse face view using $3 \mathrm{D}$ sonography to diagnose cleft lip and palate in the antenatal period [41, 42]. While prenatal diagnosis of cleft is readily attainable using conventional 2D sonography, cleft palate is more difficult to identify especially if it is an associated anomaly [43]. Platt et al. believed that the accurate diagnosis of craniofacial malformations can be enhanced with 3D sonography [44]. Rotten and Levaillant (2004) have also reported that inclusion of $3 \mathrm{D}$ and $4 \mathrm{D}$ ultrasound imaging allows easier and more precise evaluation of the different cleft constituents [45].

2.5. Effects. Affected children have a range of functional as well as aesthetic problems and these include feeding difficulties at birth due to problems with oral seal, swallowing and nasal regurgitation, hearing difficulties due to abnormalities in the palatal musculature, and speech difficulties due to nasal escape articulation problems and dental problems $[4,39,46]$. Many parents express a feeling of loss of control that despite their plans for a "healthy" pregnancy, they have been unable to control the outcome. Mothers often report feelings of resentment, hurt, and disappointment after discovering that their child has an OFC [47]. 
Studies have found decreased quality of life of adolescents with congenital and acquired facial malformations compared with unaffected adolescents as well as frequent reporting of stigmatization experiences [48, 49]. Quality of life also decreased with the individuals' perceptions of increasing severity of facial malformations [50].

\subsection{Syndromic and Nonsyndromic Clefts}

2.6.1. Syndromic Clefts. Cleft lip or palate can be seen as an associated feature in $\geq 300$ syndromes $[3,10]$. Syndromic $\mathrm{CL} / \mathrm{P}$ cases also indicate a genetic aetiology, because more than 400 known syndromes include orofacial clefting, and many of these follow classic Mendelian inheritance patterns [51]. Cleft palate with ankyloglossia (CPX; MIM 303400) is inherited as a semidominant X-linked disorder previously described in several large families of different ethnic origins and has been the subject of several studies that localized the causative gene to Xq21. Positional cloning identified the CPX locus as the gene encoding T-BOX 22 (TBX22) [52]. TBX22 is a member of the T-box containing transcription factor gene family that is conserved throughout metazoan evolution. Van der Woude syndrome (VWS) (OMIM 119300) is the most common autosomal dominant disorder which is always associated with cleft lip or palate (CL/P) [53]. Interferon regulatory factor 6 (IRF6) which is located in chromosome 1 is the major gene that is associated with VWS [54, 55], and later its variants were found to be significantly associated with nonsyndromic clefts $[51,56]$. The Wolf-Hirschhorn syndrome (WHS) (OMIM 194190), which is caused by the partial deletion of the short arm of chromosome $4(4 \mathrm{p})$, is also characterized by oral clefts [57].

2.6.2. Non-Syndromic Clefts. Gene identification for nonsyndromic cleft lip and palate is difficult because of the varying levels of its penetrance, sex differences, and other environmental factors [58]. The complex natures of the nonsyndromic clefts that are attributed to the multiple interacting genes conferring moderate effects have been proposed to provide susceptibility to orofacial clefts [59-61]. Studies on these syndromes have given sufficient clues to identify the genes that cause the non-syndromic clefts [62]. Fluorescence in situ hybridization (FISH) analysis of eight Finnish WHS patients revealed five patients not having one copy of Msx1 with oligodontia while the other three had two hybridization signals of which one patient presented with the only case of cleft palate [63]. Analysis of a Dutch family with CL/P, CP, and selective tooth genesis revealed a heterozygous nonsense mutation in $M s x 1$ gene. Furthermore, complete sequencing of the Msxl gene in 1000 unrelated CL/P individuals showed that mutations in $M s x 1$ alone could account for $2 \%$ of isolated CL/P [64].

\section{Related Animal Models}

Scientists from diverse fields have gravitated to the mouse because of its close genetic and physiological similarities to humans, as well as the ease with which its genome can be manipulated and analyzed [65]. Furthermore, the development of the embryonic face is similar in mice and humans [66]. The development of the upper lip has been well reviewed and presented for use of the CL/P mutants recently [67]. Mouse mutants with disruption in genes such as Gli2, Gli3, $T g f \beta 2$, and Hoxa2 result in CL/P through disturbance to cranial neural crest (CNC) migration and differentiation [6870]. Several genes have been implicated in palatal mesenchymal proliferation such as $M s x 1$ and $L h x 8$, where CP is seen in the respective null mice due to the palatal shelves failing to meet in the horizontal plane [71, 72]. Mice lacking Msxl function manifest a cleft of secondary palate, a deficiency of alveolar mandible and maxilla, and a failure of tooth development $[69,73]$. Mice lacking EDN1 have shown several craniofacial abnormalities, including cleft palate [70].

\section{Economic Impact}

Treatment of cleft lip and palate anomalies requires years of specialized care and is costly. The average lifetime medical cost for treatment of one individual affected with a cleft lip and palate is $\$ 100,000$ [74]. Although successful treatment of the cosmetic and functional aspects of orofacial cleft anomalies is now possible, it is still challenging, lengthy, costly, and dependent on the skills and experience of a medical team. This especially applies to surgical, dental, and speech therapies [40]. The mean and median costs for children $\leq 10$ years of age with an orofacial cleft were eight times higher than those for children of the same age without an orofacial cleft. Mean costs for infants with a cleft and another major unrelated defect were 25 times higher than those for an infant without a cleft and five times higher than those for infants with an isolated cleft with patients continuously enrolled in a fee-for-service [75].

\section{Management}

Services and treatment for children with OFCs vary depending on the severity of the cleft; the presence of associated syndromes, other birth defects, or both; and the child's age and needs [76].

5.1. Surgical Management. Orofacial clefts generally require surgical repair. Often multiple surgeries are needed to reconstruct the lip and palate [39]. A palatoplasty is the procedure utilized to close the palate, restore the velopharyngeal sphincter, and help speech function and other processes [77]. The optimum approach to the treatment of children born with cleft defects is a multidisciplinary approach which involves combined efforts of a pediatrician, orthodontist, specialist nurse, cleft surgeon, speech therapist, and ear, nose, and throat specialist to provide the best combined expertise to ensure that the correct interventions are carried out at the appropriate time and to ensure the best functional and aesthetic result [78]. Many children will need additional surgeries as they get older. Surgical repair can improve the look and appearance of a child's face; it also may improve breathing, and shearing, speech and language [79]. 
5.2. Medical Management. The supplementation of folic acid currently recommended to protect against neural tube defects is $0.4 \mathrm{mg}$ per day, twice the current average daily intake for women of $0.2 \mathrm{mg}$ [80]. It has been suggested that maternal folic acid supplementation plays a role in the prevention of non-syndromic orofacial clefts, that is, cleft lip with or without cleft palate $(C L \pm P)$ [81]. Several studies have reported decreased rates of cleft lip and palate with folic acid use [82-85]. Some ambiguity of the studies may be explained by a recent study that found that oral cleft risk can be reduced only by high doses of folic acid consumed at the time of lip and palate formation [86]. Maternal multivitamin use has also been found to result in a significant reduction in cleft palate risk and a nonsignificant reduction in cleft lip risk [87].

5.3. Psychological Management. The psychological care of the patient with a cleft begins at the time of diagnosis, even if this is before birth. An accurate diagnosis is critical to the process of counseling families. It is the responsibility of the referral centre to define the nature of the structural defect with as much precision as possible. This helps the family to visualize the child and to discuss feeding, especially breastfeeding. It also helps when informing about timing and type of surgery. To plan for the future, parents need to discuss the management and likely the treatment pathway at their own pace and at their own time, so that they are able to absorb the information [88]. Delayed repair of cleft can lead to impaired family and societal relationships with potential long-term psychological effects on the child. As the child matures and faces the task of individuation from the family, there may be a need for psychological work, and since adulthood provides its own set of challenges to the individual, there is potential for further psychological interventions throughout this period of life. Parents need reassurance, support, and time to assimilate the information to be able to provide the child with the support and care needed.

5.4. Social Management. Strong parent support networks may help to prevent the development of negative self-concept in children with cleft palate [89], so it is important that parents discuss with their children ways to handle negative social situations related to their cleft lip and/or cleft palate [3].

5.5. Other Forms of Treatment. For other treatments such as hearing assessment, speech and language therapy, and dentofacial development and treatment, psychologist or other mental specialists are required to ensure effective functioning of the body organs and systems $[46,89]$. The role of craniofacial team in the management of cleft lip \pm palate cannot be understated. A craniofacial team is a multidisciplinary team which provides multidisciplinary consultations, diagnosis, treatment planning, and procedures for a range of craniofacial anomalies and syndromes [3]. Teamwork is highly recommended in the management of persons with OFC. This team is much dedicated to ensuring that persons with the condition are offered the necessary help, care, and support to help them have a better life.

\section{Prevention}

It is necessary to understand genetic and environmental causes of syndromic and non-syndromic OFCs in order to prevent them. Having an understanding of multifactorial a etiology helps direct attention toward prevention. It helps to understand much better our own health problems and modify our lifestyle and diet in order to prevent "environmental factors" from triggering the mutated genes inherited from our parents [90]. Genetic counseling, taking of prenatal vitamins and tobacco or alcohol intake should be taken into consideration before and during pregnancy [90]. Research has also recommended folic acid intake as a means of controlling clefts and it is therefore advisable for women to take folic acid as a daily dietary supplement before and in the early weeks of pregnancy [91].

\section{Conclusion}

Education and awareness on orofacial clefts in general should be promoted so that preventive measures can be put in place and persons suffering from the condition can be well attended to and catered for. Orofacial clefts impact on a person's quality of life hence the need for better management of this abnormality. There is a need for more studies to be carried out on cleft genetics since it would help to identify some predisposing factors to the development of clefts. Also genetic counseling units should be set up to counsel persons with the abnormality and also expectant mothers.

\section{References}

[1] G. L. Wehby and J. C. Murray, "Folic acid and orofacial clefts: a review of the evidence," Oral Diseases, vol. 16, no. 1, pp. 11-19, 2010.

[2] P. Mossey and J. Little, "Addressing the challenges of cleft lip and palate research in India," Indian Journal of Plastic Surgery, vol. 42, no. 1, pp. S9-S18, 2009.

[3] Cleft Lip and Palate, http://en.wikipedia.org/wiki/Cleft_lip_ and_palate.

[4] B. J. Leonard and J. D. Brust, "Self-concept of children and adolescents with cleft lip and/or palate," Cleft Palate-Craniofacial Journal, vol. 28, no. 4, pp. 347-353, 1991.

[5] E. Ellis III, "Management of patients with orofacial clefts," in Contemporary Oral and Maxillofacial Surgery, pp. 623-645, Mosby, St. Louis, Mo, USA, 4th edition, 2003.

[6] F. Blanco-Davila, "Incidence of cleft lip and palate in the northeast of Mexico: a 10-year study," The Journal of Craniofacial Surgery, vol. 14, no. 4, pp. 533-537, 2003.

[7] T. D. Gregg, D. Boyd, and A. Richardson, "The incidence of cleft lip and palate in Northern Ireland from 1980-1990," British Journal of Orthodontics, vol. 21, no. 4, pp. 387-392, 1994.

[8] T. Hartridge, H. M. Illing, and J. R. Sandy, "The role of folic acid in oral clefting," British Journal of Orthodontics, vol. 26, no. 2, pp. 115-120, 1999.

[9] K. J. Rothman, L. L. Moore, M. R. Singer, U. S. D. T. Nguyen, S. Mannino, and A. Milunsky, "Teratogenicity of high vitamin A intake," The New England Journal of Medicine, vol. 333, no. 21, pp. 1369-1373, 1995. 
[10] White Memorial Medical Center (Adventist Health) Cleft Palate Program, http://www.whitememorial.com/medical-services/ cleft-palate-faqs.

[11] J. C. Murray and B. C. Schutte, "Cleft palate: players, pathways, and pursuits," The Journal of Clinical Investigation, vol. 113, no. 12, pp. 1676-1678, 2004.

[12] L. Scapoli, J. Marchesini, M. Martinelli et al., "Investigation of the W185X nonsense mutation of PVRL1 gene in Italian nonsyndromic cleft lip and palate patients," American Journal of Medical Genetics, vol. 127, no. 2, p. 211, 2004.

[13] M. M. Tolarova and J. Cervenka, "Classification and birth prevalence of orofacial clefts," American Journal of Medical Genetics, vol. 75, pp. 126-137, 1998.

[14] J. C. Murray, S. Daack-Hirsch, K. H. Buetow et al., "Clinical and epidemiologic studies of cleft lip and palate in the Philippines," Cleft Palate-Craniofacial Journal, vol. 34, pp. 7-10, 1997.

[15] S. K. Das, R. S. Runnels, J. C. Smith, and H. H. P. Cohly, "Epidemiology of cleft lip and cleft palate in Mississippi," Southern Medical Journal, vol. 88, no. 4, pp. 437-442, 1995.

[16] Cleft Lip and Cleft Palate, http://www.medicinenet.com/cleft_ palate_and_cleft_lip/article.htm.

[17] L. M. Iregbulem, "The incidence of cleft lip and palate in Nigeria," Cleft Palate Journal, vol. 19, no. 3, pp. 201-205, 1982.

[18] A. A. Khan, "Congenital malformations in African neonates in Nairobi," Journal of Tropical Medicine and Hygiene, vol. 68, no. 11, pp. 272-274, 1965.

[19] B. C. Msamati, P. S. Igbigbi, and J. E. Chisi, "The incidence of cleft lip, cleft palate, hydrocephalus and spina bifida at Queen Elizabeth Central Hospital, Blantyre, Malawi," Central African Journal of Medicine, vol. 46, no. 11, pp. 292-296, 2000.

[20] A. M. Suleiman, S. T. Hamzah, M. A. Abusalab, and K. T. Samaan, "Prevalence of cleft lip and palate in a hospital-based population in the Sudan," International Journal of Paediatric Dentistry, vol. 15, no. 3, pp. 185-189, 2005.

[21] P. Agbenorku, M. Agbenorku, A. Iddi et al., "A study of cleft lip/palate in a community in the South East of Ghana," European Journal of Plastic Surgery, vol. 34, no. 4, pp. 267-272, 2011.

[22] Cleft palate Foundation. Genetics and You, http://www.cleftline .org/docs/Booklets/GEN-01.pdf.

[23] B. C. Schutte and J. C. Murray, "The many faces and factors of orofacial clefts," Human Molecular Genetics, vol. 8, no. 10, pp. 1853-1859, 1999.

[24] Birth Defect Risk Factor Series: Oral Clefts, February 2012.

[25] J. Little, A. Cardy, and R. G. Munger, "Tobacco smoking and oral clefts: a meta-analysis," Bulletin of the World Health Organization, vol. 82, no. 3, pp. 213-218, 2004.

[26] S. V. Spilson, H. J. E. Kim, and K. C. Chung, "Association between maternal diabetes mellitus and newborn oral cleft," Annals of Plastic Surgery, vol. 47, no. 5, pp. 477-481, 2001.

[27] E. E. Castilla, J. S. Lopez-Camelo, and H. Campana, "Altitude as a risk factor for congenital anomalies," American Journal of Medical Genetics, vol. 86, no. 1, pp. 9-14, 1999.

[28] A. R. Vieira, I. M. Orioli, and J. C. Murray, "Maternal age and oral clefts: a reappraisal," Oral Surgery, Oral Medicine, Oral Pathology, Oral Radiology, and Endodontics, vol. 94, no. 5, pp. 530-535, 2002.

[29] J. Yang, S. L. Carmichael, M. Canfield, J. Song, and G. M. Shaw, "Socioeconomic status in relation to selected birth defects in a large multicentered US case-control study," American Journal of Epidemiology, vol. 167, no. 2, pp. 145-154, 2008.
[30] I. P. C. Krapels, I. A. L. M. van Rooij, R. A. Wevers et al., "Myo-inositol, glucose and zinc status as risk factors for nonsyndromic cleft lip with or without cleft palate in offspring: a case-control study," BJOG: An International Journal of Obstetrics and Gynaecology, vol. 111, no. 7, pp. 661-668, 2004.

[31] I. A. L. M. van Rooij, C. Vermeij-Keers, L. A. J. Kluijtmans et al., "Does the interaction between maternal folate intake and the methylenetetrahydrofolate reductase polymorphisms affect the risk of cleft lip with or without cleft palate?" American Journal of Epidemiology, vol. 157, no. 7, pp. 583-591, 2003.

[32] H. P. Erzsébet, M. Szunyogh, J. Métnek et al., "Drug treatment during pregnancy and isolated orofacial clefts in hungary," The Cleft Palate-Craniofacial Journal, vol. 44, no. 2, pp. 194-202, 2007.

[33] A. Jugessur, A. J. Wilcox, R. T. Lie et al., "Exploring the effects of methylenetetrahydrofolate reductase gene variants C677T and A1298C on the risk of orofacial clefts in 261 Norwegian caseparent triads," American Journal of Epidemiology, vol. 157, no. 12, pp. 1083-1091, 2003.

[34] T. H. Beaty, N. E. Maestri, J. B. Hetmanski et al., "Testing for interaction between maternal smoking and TGFA genotype among oral cleft cases born in Maryland 1992-1996," Cleft Palate-Craniofacial Journal, vol. 34, pp. 447-454, 1997.

[35] E. J. Lammer, G. M. Shaw, D. M. Iovannisci, and R. H. Finnell, "Periconceptional multivitamin intake during early pregnancy, genetic variation of acetyl-N-transferase 1 (NAT1), and risk for orofacial clefts," Birth Defects Research A, vol. 70, no. 11, pp. 846852, 2004.

[36] R. G. Munger, P. A. Romitti, S. Daack-Hirsch, T. L. Burns, J. C. Murray, and J. Hanson, "Maternal alcohol use and risk of orofacial cleft birth defects," Teratology, vol. 54, pp. 27-33, 1996.

[37] L. B. Holmes, D. F. Wyszynski, and E. Lieberman, "The AED (antiepileptic drug) pregnancy registry: a 6-year experience," Archives of Neurology, vol. 61, no. 5, pp. 673-678, 2004.

[38] B. Källín, "Maternal drug use and infant cleft lip/palate with special reference to corticoids," Cleft Palate-Craniofacial Journal, vol. 40, no. 6, pp. 624-628, 2003.

[39] Utah Department of Health: Striving to Prevent Birth Defects, Orofacial Clefts at a Glance, http://www.health.utah.gov/birth defect/defects/orofacial.html.

[40] Centers for Disease Control and Prevention, Birth Defects: Facts about Cleft Lip and Cleft Palate, http://www.cdc.gov/ ncbddd/birthdefects/cleftlip.html.

[41] S. Campbell and C. C. Lees, "The three-dimensional reverse face (3D RF) view for the diagnosis of cleft palate," Ultrasound in Obstetrics and Gynecology, vol. 22, no. 5, pp. 552-554, 2003.

[42] S. Campbell, C. Lees, G. Moscoso, and P. Hall, "Ultrasound antenatal diagnosis of cleft palate by a new technique: the 3D 'reverse face' view,' Ultrasound in Obstetrics and Gynecology, vol. 25, no. 1, pp. 12-18, 2005.

[43] S. J. Walker, R. H. Ball, C. J. Babcook, and M. M. Feldkamp, "Prevalence of aneuploidy and additional anatomic abnormalities in fetuses and neonates with cleft lip with or without cleft palate: a population-based study in Utah," Journal of Ultrasound in Medicine, vol. 20, no. 11, pp. 1175-1180, 2001.

[44] L. D. Platt, G. R. DeVore, and D. H. Pretorius, "Improving cleft palate/cleft lip antenatal diagnosis by 3-dimensional sonography: the "flipped face" view," Journal of Ultrasound in Medicine, vol. 25, no. 11, pp. 1423-1430, 2006.

[45] D. Rotten and J. M. Levaillant, "Two- and three-dimensional sonographic assessment of the fetal face. 2. Analysis of cleft lip, 
alveolus and palate," Ultrasound in Obstetrics and Gynecology, vol. 24, no. 4, pp. 402-411, 2004.

[46] M. L. Speltz, G. C. Armsden, and S. S. Clarren, "Effects of craniofacial birth defects on maternal functioning postinfancy," Journal of Pediatric Psychology, vol. 15, no. 2, pp. 177-196, 1990.

[47] T. D. Topolski, T. C. Edwards, and D. L. Patrick, "Quality of life: how do adolescents with facial differences compare with other adolescents?" Cleft Palate-Craniofacial Journal, vol. 42, no. 1, pp. 25-32, 2005.

[48] R. P. Strauss, B. L. Ramsey, T. C. Edwards et al., "Stigma experiences in youth with facial differences: a multi-site study of adolescents and their mothers," Orthodontics \& Craniofacial Research, vol. 10, no. 2, pp. 96-103, 2007.

[49] D. L. Patrick, T. D. Topolski, T. C. Edwards et al., "Measuring the quality of life of youth with facial differences," Cleft PalateCraniofacial Journal, vol. 44, no. 5, pp. 538-547, 2007.

[50] D. Pelchat, J. Bisson, N. Ricard, M. Perreault, and J. M. Bouchard, "Longitudinal effects of an early family intervention programme on the adaptation of parents of children with a disability," International Journal of Nursing Studies, vol. 36, no. 6, pp. 465-477, 1999.

[51] M. Lees, "Genetics of cleft lip and palate," in Management of Cleft Lip and Palate, A. C. H. Watson, D. A. Sell, and P. Grunwell, Eds., pp. 87-104, Whurr Publishers, London, UK, 2001.

[52] C. Braybrook, K. Doudney, A. C. B. Marçano et al., "The T-box transcription factor gene TBX22 is mutated in X-linked cleft palate and ankyloglossia," Nature Genetics, vol. 29, no. 2, pp. 179-183, 2001.

[53] A. van der Woude, "Fistula labii inferioris congenita and its association with cleft lip and palate," American Journal of Human Genetics, vol. 6, pp. 244-256, 1954.

[54] B. C. Schutte, B. C. Bjork, K. B. Coppage et al., "A preliminary gene map for the Van der Woude syndrome critical region derived from $900 \mathrm{~kb}$ of genomic sequence at 1q32-q41," Genome Research, vol. 10, no. 1, pp. 81-94, 2000.

[55] S. Kondo, B. C. Schutte, R. J. Richardson et al., "Mutations in IRF6 cause Van der Woude and popliteal pterygium syndromes," Nature Genetics, vol. 32, no. 2, pp. 285-289, 2002.

[56] T. M. Zucchero, M. E. Cooper, B. S. Maher et al., "Interferon regulatory factor 6 (IRF6) gene variants and the risk of isolated cleft lip or palate," The New England Journal of Medicine, vol. 351, no. 8, pp. 769-780, 2004.

[57] M. Morishita, R. Shiba, H. Chiyo, J. Furuyama, H. Fujita, and Y. Atsumi, "The oral manifestations of 4p-syndrome," Journal of Oral and Maxillofacial Surgery, vol. 41, no. 9, pp. 601-605, 1983.

[58] J. C. Murray, "Face facts: genes, environment, and clefts," American Journal of Human Genetics, vol. 57, no. 2, pp. 227-232, 1995.

[59] D. A. Gaspar, S. R. Matioli, R. de Cássia Pavanello et al., "Maternal MTHFR interacts with the offspring's BCL3 genotypes, but not with TGFA, in increasing risk to nonsyndromic cleft lip with or without cleft palate," European Journal of Human Genetics, vol. 12, no. 7, pp. 521-526, 2004.

[60] E. J. Lammer, G. M. Shaw, D. M. Iovannisci, and R. H. Finnell, "Maternal smoking, genetic variation of glutathione Stransferases, and risk for orofacial clefts," Epidemiology, vol. 16, no. 5, pp. 698-701, 2005.

[61] G. M. Shaw, D. M. Iovannisci, W. Yang et al., "Endothelial nitric oxide synthase (NOS3) genetic variants, maternal smoking, vitamin use, and risk of human orofacial clefts," American Journal of Epidemiology, vol. 162, no. 12, pp. 1207-1214, 2005.
[62] P. Stanier and G. E. Moore, "Genetics of cleft lip and palate: syndromic genes contribute to the incidence of non-syndromic clefts," Human Molecular Genetics, vol. 13, no. 1, pp. R73-R81, 2004.

[63] P. Nieminen, J. Kotilainen, Y. Aalto, S. Knuutila, S. Pirinen, and I. Thesleff, "MSX1 gene is deleted in Wolf-Hirschhorn syndrome patients with oligodontia," Journal of Dental Research, vol. 82, no. 12, pp. 1013-1017, 2003.

[64] P. A. Jezewski, A. R. Vieira, C. Nishimura et al., "Complete sequencing shows a role for MSX1 in non-syndromic cleft lip and palate," Journal of Medical Genetics, vol. 40, no. 6, pp. 399407, 2003.

[65] T. Thyagarajan, S. Totey, M. J. S. Danton, and A. B. Kulkarni, "Genetically altered mouse models: the good, the bad, and the ugly," Critical Reviews in Oral Biology and Medicine, vol. 14, no. 3, pp. 154-174, 2003.

[66] V. M. Diewert and K. Y. Wang, "Recent advances in primary palate and midface morphogenesis research," Critical Reviews in Oral Biology and Medicine, vol. 4, no. 1, pp. 111-130, 1992.

[67] R. Jiang, J. O. Bush, and A. C. Lidral, "Development of the upper lip: morphogenetic and molecular mechanisms," Developmental Dynamics, vol. 235, no. 5, pp. 1152-1166, 2006.

[68] R. Mo, A. M. Freer, D. L. Zinyk et al., "Specific and redundant functions of Gli2 and Gli3 zinc finger genes in skeletal patterning and development," Development, vol. 124, no. 1, pp. 113-123, 1997.

[69] L. P. Sanford, I. Ormsby, A. C. Gittenberger-de Groot et al., "TGF $\beta 2$ knockout mice have multiple developmental defects that are non-overlapping with other TGF $\beta$ knockout phenotypes," Development, vol. 124, no. 13, pp. 2659-2670, 1997.

[70] N. A. Quaderi, S. Schweiger, K. Gaudenz et al., "Opitz G/BBB syndrome, a defect of midline development, is due to mutations in a new RING finger gene on Xp22," Nature Genetics, vol. 17, no. 3, pp. 285-291, 1997.

[71] F. M. Rijli, M. Mark, S. Lakkaraju, A. Dierich, P. Dolle, and P. Chambon, "A homeotic transformation is generated in the rostral branchial region of the head by disruption of Hoxa-2, which acts as a selector gene," Cell, vol. 75, no. 7, pp. 1333-1349, 1993.

[72] I. Satokata and R. Maas, "Msxl deficient mice exhibit cleft palate and abnormalities of craniofacial and tooth development," Nature Genetics, vol. 6, no. 4, pp. 348-356, 1994.

[73] Y. Zhao, Y. J. Guo, A. C. Tomac et al., "Isolated cleft palate in mice with a targeted mutation of the LIM homeobox gene Lhx8," Proceedings of the National Academy of Sciences of the United States of America, vol. 96, no. 26, pp. 15002-15006, 1999.

[74] N. J. Waitzman, P. S. Romano, and R. M. Scheffler, "Estimates of the economic costs of birth defects," Inquiry, vol. 31, no. 2, pp. 188-205, 1994.

[75] S. L. Boulet, S. D. Grosse, M. A. Honein, and A. CorreaVillaseñor, "Children with orofacial clefts: health-care use and costs among a privately insured population," Public Health Reports, vol. 124, no. 3, pp. 447-453, 2009.

[76] American Cleft Palate-Craniofacial Association, Parameters for Evaluation and Treatment of Patients with Cleft Lip/Palate or other Craniofacial Anomalies, American Cleft PalateCraniofacial Association, Chapel Hill, NC, USA, 2009.

[77] J. Brailsford, D. D. Smith, A. K. Lizarraga, and L. E. Bermudez, "Surgical management of patients with cleft palate," OR Nurse, vol. 4, no. 3, pp. 16-25, 2010. 
[78] WHO. Reports, Human Genetics Programme, "Management of non-communicable diseases. International collaborative research on craniofacial anomalies," in Global Strategies Towards Reducing the Health Care Burden of Craniofacial Anomalies, P. A. Mossey, R. Munger, J. C. Murray, and W. C. Shaw, Eds., WHO, Geneva, Switzerland, 2002.

[79] M. M. Yazdy, A. R. Autry, M. A. Honein, and J. L. Frias, "Use of special education services by children with orofacial clefts," Birth Defects Research A, vol. 82, no. 3, pp. 147-154, 2008.

[80] H. McNulty, "Folate requirements for health in different population groups," British Journal of Biomedical Science, vol. 52, no. 2, pp. 110-119, 1995.

[81] "Global strategies to reduce the health-care burden of craniofacial anomalies," Report of WHO Meetings on International Collaborative Research on Craniofacial Anomalies, WHO, Geneva, Switzerland, 2001.

[82] F. A. Malek, K. U. Möritz, J. Fanghänel, and V. Bienengräber, "Sex-related differences in procarbazine-induced cleft palate and microgenia and the anti-teratogenic effect of prenatal folic acid supplementation in rats," Annals of Anatomy, vol. 185, no. 5, pp. 465-470, 2003.

[83] J. Mulinare, J. D. Erickson, L. M. James et al., "Does periconceptional use of multivitamins reduce the occurrence of birth defects?" American Journal of Epidemiology, vol. 141, supplement 3, 1995.

[84] R. Munger, P. Romitti, N. West et al., "Maternal intake of folate, vitamin B-12, and zinc and risk of orofacial cleft birth defects," American Journal of Epidemiology, vol. 145, supplement 30, 1997.

[85] G. M. Shaw, V. Nelson, S. L. Carmichael, E. J. Lammer, R. H. Finnell, and T. H. Rosenquist, "Maternal periconceptional vitamins: interactions with selected factors and congenital anomalies?" Epidemiology, vol. 13, no. 6, pp. 625-630, 2002.

[86] A. E. Czeizel, L. Tímár, and A. Sárközi, "Dose-dependent effect of folic acid on the prevention of orofacial clefts," Pediatrics, vol. 104, no. 6, p. e66, 1999.

[87] M. M. Werler, C. Hayes, C. Louik, S. Shapiro, and A. A. Mitchell, "Multivitamin supplementation and risk of birth defects," American Journal of Epidemiology, vol. 150, no. 7, pp. 675-682, 1999.

[88] P. D. Hodgkinson, S. Brown, D. Duncan et al., "Management of children with cleft lip and palate: a review describing the application of multidisciplinary team working in this condition based upon the experiences of a regional cleft lip and palate centre in the United Kingdom," Fetal and Maternal Medicine Review, vol. 16, no. 1, pp. 1-27, 2005.

[89] L. Bristow and S. Bristow, Making Faces: Logan's Cleft Lip and Palate Story, Pulsus Group, Ontario, Canada, 2007.

[90] M. M. Tolarová, D. Poulton, M. M. Aubert et al., "Pacific craniofacial team and cleft prevention program," Journal of the California Dental Association, vol. 34, no. 10, pp. 823-830, 2006.

[91] A. Habel and M. Lees, "Folic acid in the prevention of cleft lip and palate," CLAPA News, no. 12, 2000, http://www.clapa.com/ medical/article/333/. 


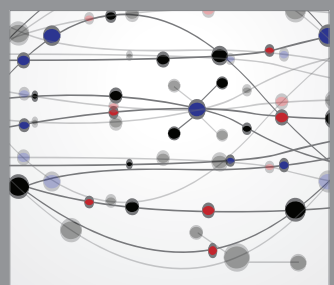

The Scientific World Journal
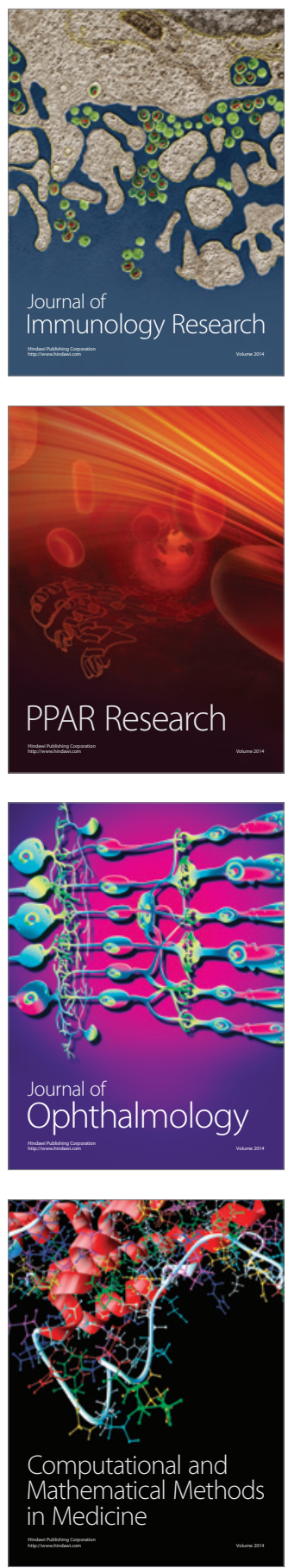

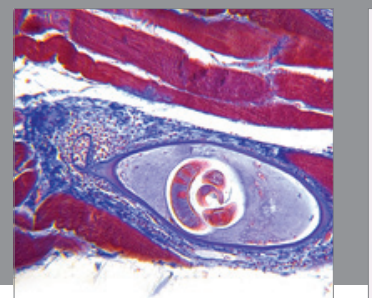

Gastroenterology

Research and Practice
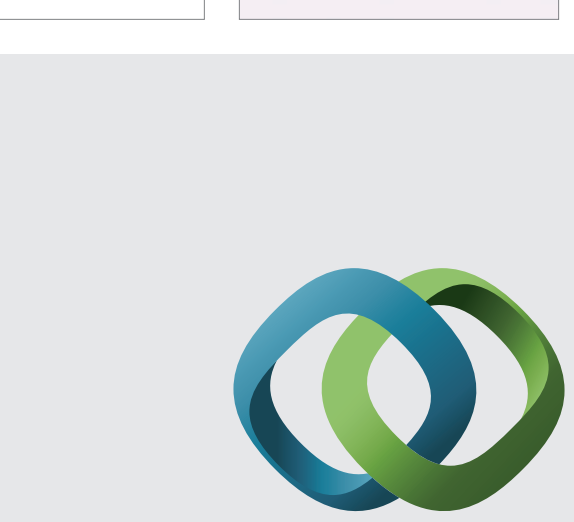

\section{Hindawi}

Submit your manuscripts at

http://www.hindawi.com
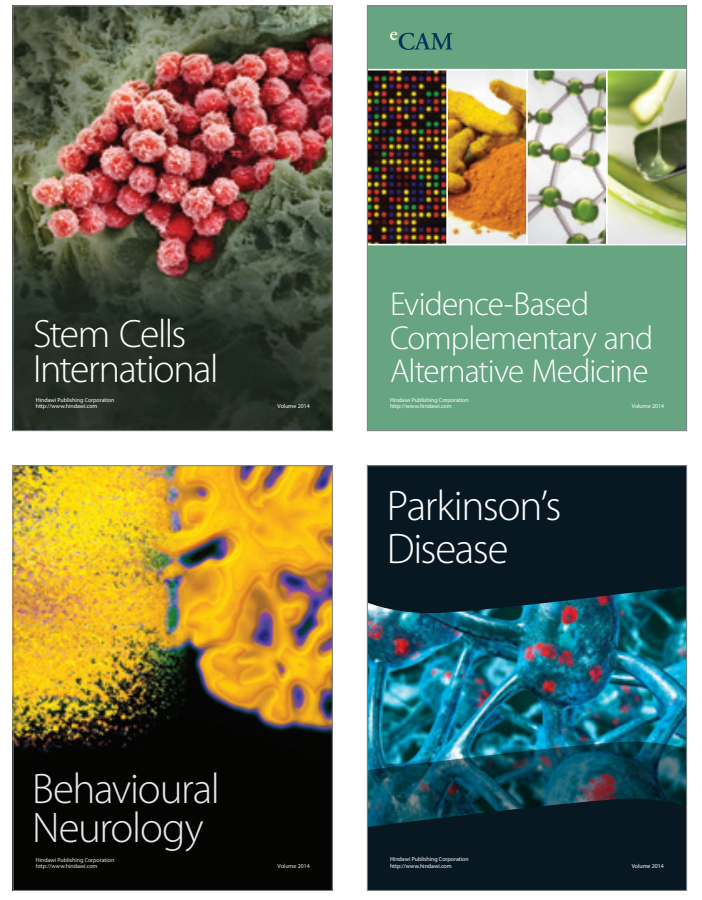
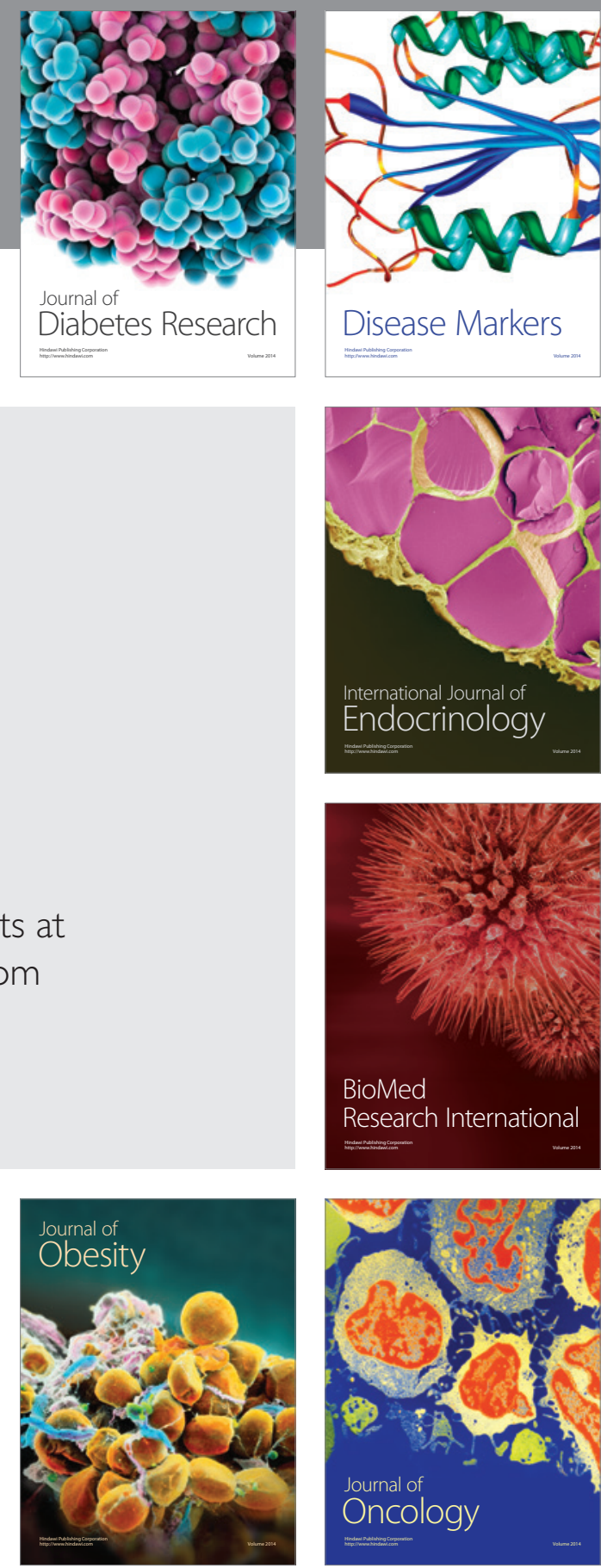

Disease Markers
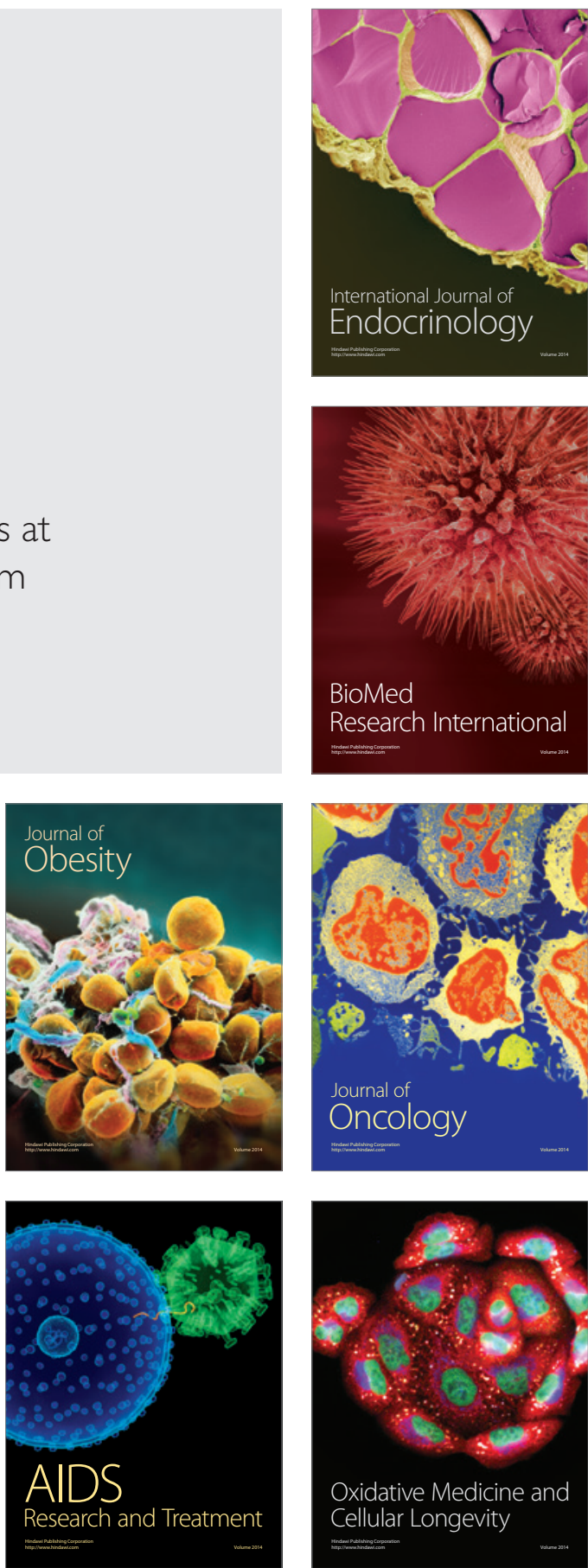